\title{
Multiple $b$ values of diffusion-weighted magnetic resonance imaging in evaluation of solid head and neck masses
}

\author{
Rania Sobhy Abou khadrah * (D) and Haytham Haroon Imam
}

\begin{abstract}
Background: Differentiation between malignant and benign masses is essential for treatment planning and helps in improving the prognosis of malignant tumors; the aim of this work is to determine the role of diffusionweighted magnetic resonance imaging (DW-MRI) and the apparent diffusion coefficient (ADC) in the differentiation between benign and malignant solid head and neck masses by comparing diagnostic performance of low $b$ values $\left(0.50\right.$ and $400 \mathrm{~s} / \mathrm{mm}^{2}$ ) versus high $b$ values $\left(800\right.$ and $\left.1000 \mathrm{~s} / \mathrm{mm}^{2}\right)$ and comparing the result with histopathological finding.

Results: The study included 60 patients (34 male and 26 female) with solid head and neck masses $>1 \mathrm{~cm}$ who referred to radiodiagnosis department for MRI evaluation. Multiple $b$ values were used $50,400,800$, and $1000 \mathrm{~s} / \mathrm{mm}^{2}$ (at least $2 b$ values). DWI and ADC value of all 60 patients were acquired. Mean ADC values of both malignant and benign masses were statistically measured and compared, and cut off value was determined. Solid head and neck masses in our study DWI with the use of high $b$ value 800 and $1000 \mathrm{~s} / \mathrm{mm}^{2}$ were of higher significance ( $P$ value $0.001 *)$. There was a significant difference in the mean ADC value between benign and malignant masses $(P<0.01)$; solid masses were divided into 2 categories: (a) malignant lesions $46.7 \%(n=28)$ with mean ADC value $(0.82 \pm 0.19) \times$ $10^{-3} \mathrm{~s} / \mathrm{mm}^{2}$ and (b) benign lesions $53.3 \%(n=32)$ with mean ADC value $\left.(2.05 \pm 0.46) \times 10^{-3} \mathrm{~s} / \mathrm{mm}^{2}\right)$ with ADC cutoff value of $1.0 \times 10^{-3} \mathrm{~s} / \mathrm{mm}^{2}$ and $94 \%$ sensitivity, $93 \%$ specificity, negative predictive value (NPV) $=94 \%$, positive predictive value (PPV) 93\%, and an accuracy of $93.5 \%$.

Conclusion: The DWI with ADC mapping were valuable as non-invasive tools in differentiating between benign and malignant solid head and neck masses. The use of high $b$ value 800 and $1000 \mathrm{~s} / \mathrm{mm}^{2}$ was of higher significance $(P$ value $0.001^{*}$ ) in differentiation between benign and malignant lesion than that with low $b$ values 0,50 , and $400 \mathrm{~s} / \mathrm{mm}^{2}$ (0.01). The mean ADC values were significantly lower in malignant solid masses. Attention had to be paid to the choice of $b$ values in MRI-DWI in the head and neck region.
\end{abstract}

Keywords: Diffusion-weighted imaging (DWI), Apparent diffusion coefficient (ADC), b value, Benign mass, Malignant mass

\section{Background}

The head and neck regions were constituted to have high anatomical and functional difficulties, making the accurate diagnosis and staging of regional tumors a challenging task. Many lesions are detected at clinical examination, but imaging techniques are also necessary for accurate characterization of biological aggressiveness and better staging and management [1].

\footnotetext{
* Correspondence: rotinia2009@gmail.com

Radio Diagnosis and Medical Imaging, Radiology Department, College of Medicine, Tanta University Hospital, Faculty of Medicine, Tanta University, 15 Ebn elphared Street, Tanta, Gharbia Governorate 31511, Egypt
}

MRI sequences provided us with very accurate data about tumor size, site, and morphological criteria of tumors in the head and neck areas. However, it was not enough for the evaluation of biological behavior of tumors. Functional MRI imaging techniques were newly developed which can provide us with information on biological and functional aspects of tumor vascularization and internal microarchitecture [2].

Diffusion-weighted imaging (DWI) was an emerging non-invasive functional MRI technique made without administration of intravenous contrast agent and had 
reliable ability in discrimination between benign and malignant tissues [3].

The diffusion gradient strength named as $b$ value [s/ $\mathrm{mm}^{2}$ ] which was dependent on duration, amplitude, and the time between applications of the sensitizing gradient; therefore, to increase the $b$ value during DW-MRI, a greater amplitude of the diffusion-sensitizing gradient is typically applied [4].

With increasing $b$ values, image sensitivity to the detection of restricted diffusion became high; signal loss resulting from the dephasing due to the movement of the water molecules between the different opposing gradients was proportional to the degree of movement of water molecules and the $b$ value [5].

Although DW-MRI in diagnosis of head and neck masses had been well analyzed in previous studies, the choice of suitable $b$ value for imaging is still a diagnostic dilemma as factors causing passive diffusion, such as capillary perfusion, can contribute to decreased signal-to-noise ratio (SNR) in low $b$ value DW-MRI. So low $b$ value DWMRI became less qualitative and more quantitative, since it must be based on complex ADC calculations [6].

DWI was used to evaluate microscopic water diffusion within tissues which measured by means of apparent diffusion coefficient (ADC), areas of low ADC values within tumors of different regions correlate with areas of increased cellularity within tumors. Moreover, DWI had been used as a powerful imaging biomarker of cancer [7].

Many studies tried to evaluate the role of DW-MRI in head and neck masses with trials to put technical standardization, as results obtained depend on selection of $b$ values. Image quality could be impeded due to different factors as magnetic field inhomogeneity and improper placement of receiver coils; this reflected on the interpretation of DWI in the head and neck masses [8].

Herein, we tried to focus on solid head and neck masses only and tried to determine whether the low or high $b$ values as technical point were suitable enough for better quantitative and qualitative characterization.

\section{Methods}

Our prospective study includes 60 patients (28 female and 34 male) with mean age $57.34 \pm 17.77$ years; they were referred to MRI unit in our institution, for evaluation of solid head and neck masses in the period of May 2018 to May 2019; written informed consent was taken from all patients, and ethical committee approval was taken.

\section{Patient population}

Inclusion criteria: Patients with both totally and partially solid masses diagnosed either clinically or by US. Exclusion criteria: Patients with a pure cystic lesion, small masses less than $1 \mathrm{~cm}$; patients with previous surgical or medical intervention by radio- or chemotherapy; patients with any metallic prosthesis; and patients known to have claustrophobia. All patients were questioned in details about the course and duration of the swelling growth, presence of pain, and history of previous intervention, when patient had multiple masses with the same histopathology, the largest one only used for ADC calculation. General examinations were done especially for signs of thyrotoxicosis and generalized lymphadenopathy and local examination for site, size, shape, borders, tenderness, and consistency of the swelling. For the previous available laboratory studies, all the collected data were documented. A final diagnosis of all patients was based on conventional histopathological studies; the specimen was achieved either by imaging-guided fine needle biopsy and cytology (FNAC) in deep lesions $(n=37,61.6 \%)$, or using the total surgical mass dissection ( $n=23,39.3 \%)$. Non-conclusive results of FNAC were obtained in 7 cases ( 2 malignant thyroid cancer, 2 metastatic anaplastic carcinomas to cervical lymph nodes, 3 squamous cell carcinoma); finally, core needle biopsy was done in this cases, and the pathology was confirmed. Only one case showed post core needle biopsy hematoma.

\section{MRI imaging technique}

Patients were examined using closed MRI (1.5 Tesla, MR Systems GE). Routine MRI examinations pre- and postcontrast were done with slice thickness $4 \mathrm{~mm}$, interslice gap of $2-3 \mathrm{~mm}$; the matrix used for all sequences was $512 \times 256$ except the DWI which was $128 \times 64$ with following parameters FSE (fast spin-echo): Axial T1 weighted (TR: $315-515 \mathrm{~ms}$, TE $8.5-32.5 \mathrm{~ms}$, field of view $20-25$ cm). Axial T2 weighted (TR 3500-5500 ms, TE 100-130 $\mathrm{ms}$, field of view $20-25 \mathrm{~cm}$ ). Diffusion WI using ( $b$ values) of $0,50,400,800$, and $1000 \mathrm{~s} / \mathrm{mm}^{2}$ with apparent diffusion coefficient (ADC) map before contrast administration and acquired in the axial plane (at least $2 b$ values). Contrast media administration: at least two orthogonal planes were obtained using gadolinium D.T.P.A with a calculated dose of $0.1 \mathrm{mmol} / \mathrm{kg}$ body weight. The imaging data were reviewed by two radiologists (one had 10 years and the other 7 years of experience in DWI-MRI reading and reporting); both qualitative and quantitative analyses were made as the lesions that retained signal on $b$ value $1000 \mathrm{~s} /$ $\mathrm{mm}^{2}$ and were hypointense on ADC maps were characterized as having restricted diffusion. The ADC is a numerical value calculated by manually placing a region of interest (ROI) over the solid portion of the tumor, taking care to avoid the cystic or necrotic parts. The two radiologists reached a consensus opinion before reviewing the pathology results. Re-evaluation of imaging after 1 month was done reaching the same previous diagnosis. The lesion contour, size, intensity, extensions, and pattern of enhancement were recorded. 
Table 1 Distribution of the studied cases according to pathology $(n=60)$

\begin{tabular}{lll}
\hline Pathology & No. & $\%$ \\
\hline Benign & 32 & 53.3 \\
Mature teratoma & 2 & 3.3 \\
Reactive lymphadenopathy & 14 & 23.3 \\
Thyroid nodules & 8 & 13.3 \\
Ameloblastoma & 2 & 3.3 \\
Submandibular adenitis & 6 & 10 \\
Malignant & 28 & 46.7 \\
Squamous cell carcinoma & 16 & 26.7 \\
Adenoid cystic carcinoma & 8 & 13.3 \\
Malignant thyroid mass & 2 & 3.3 \\
Metastatic anaplastic carcinoma & 2 & 3.3 \\
\hline
\end{tabular}

\section{Statistical analysis}

Data were designed statistically as mean \pm standard deviation $( \pm \mathrm{SD})$, range or frequencies (number of cases), and percentages when appropriate. Comparison of numerical variables between the study groups was done using the Student $t$ test for independent samples. For comparing categorical data, chi-square (v2) test was performed. Accuracy was represented using the terms sensitivity and specificity. Receiver operator characteristic (ROC) analysis was used to determine the optimum cut-off value for differentiation between malignant and benign masses; $P$ values less than 0.05 were considered statistically significant. All statistical calculations were done using computer programs SPSS (Statistical Package for the Social Science; SPSS Inc., Chicago, IL, USA) version 26.

\section{Results}

Our study included 60 patients with solid head and neck masses, 34 males (56.7\%) and 26 females (43.3\%). Their age ranged from 3 days to 82 years, mean age $57.34 \pm$ 17.77 years.

Table 2 Distribution of the studied cases according to diffusion signal intensity \% from the total at low $b$ value

\begin{tabular}{|c|c|c|c|c|c|}
\hline \multirow{2}{*}{\multicolumn{2}{|c|}{$\begin{array}{l}\text { DWI low } b \text { values } \\
\left(0,50,400 \mathrm{~s} / \mathrm{mm}^{2}\right)\end{array}$}} & & \multicolumn{2}{|l|}{ Biopsy } & \multirow[t]{2}{*}{ Total } \\
\hline & & & Benign & $\overline{\text { Malignant }}$ & \\
\hline \multirow{2}{*}{\multicolumn{2}{|c|}{ Low SI }} & $N$ & 12 & 0 & 12 \\
\hline & & $\%$ & $37.5 \%$ & $.0 \%$ & $20.0 \%$ \\
\hline \multirow{2}{*}{\multicolumn{2}{|c|}{ High SI }} & $N$ & 20 & 28 & 48 \\
\hline & & $\%$ & $62.5 \%$ & $100.0 \%$ & $80.0 \%$ \\
\hline \multirow{2}{*}{\multicolumn{2}{|c|}{ Total }} & $N$ & 32 & 28 & 60 \\
\hline & & $\%$ & $100.0 \%$ & $100.0 \%$ & $100.0 \%$ \\
\hline \multirow[t]{2}{*}{ Chi-square } & $x^{2}$ & 6.563 & & & \\
\hline & $P$ value & $0.010^{*}$ & & & \\
\hline
\end{tabular}

SI signal intensity
The solid masses were tabulated according to the different anatomical sites as lymphadenopathy $(n=24$, $40 \%)$, larynx $(n=8,13.3 \%)$, thyroid $(n=6,10 \%)$, pharynx $(n=6,10 \%)$, nasal cavity and paranasal sinus $(n=6,10 \%)$, tongue $(n=4,6.7 \%)$, zygomatic arch $(n=2,3.3 \%)$, submandibular gland $(n=2,3.3 \%)$, and mandible $(n=2,3.3 \%)$.

Histopathological analysis was done dividing the examined solid masses in our study into 2 categories: (a) malignant lesions $(n=28) 46.7 \%$ and (b) benign lesions $53.3 \%(n=32)$ as tabulated in Table 1.

Qualitative analyses of lesions were divided according to $b$ values: in low $b$ values $\left(0,50,400 \mathrm{~s} / \mathrm{mm}^{2}\right)$, benign lesions displayed low signal intensity (SI) in $37.5 \%(n=12)$ and high SI in $62.5 \%(n=20)$, while malignant lesion displayed high SI in $100.0 \%(n=28)$ (Table 2$)$.

In high $b$ values $\left(800,1000 \mathrm{~s} / \mathrm{mm}^{2}\right)$, benign lesions displayed low SI in $87.5 \%(n=28)$ and high SI in $12.5 \%$ $(n=4)$, while malignant lesion display high SI in $100 \%$ $(n=28)$ (Table 3).

ADC values of high $b$ values were obtained and recorded for all 60 solid head and neck masses detected at consensus reading. Malignant lesions group $(n=28)$ : ADC values ranged between $0.530-1.290 \mathrm{~s} / \mathrm{mm}^{2}$. The mean ADC value of malignant lesions was $0.82 \pm 0.19$ (Figs. 1, 2, and 3). Benign lesions group $(n=32)$ : ADC values ranged between 0.674 and $2.590 \mathrm{~s} / \mathrm{mm}^{2}$. The mean ADC value of the benign lesions was $2.05 \pm 0.46 \mathrm{~s} / \mathrm{mm}^{2}$. The mean ADC value of malignant lesions was lower than the mean $\mathrm{ADC}$ value of benign lesions. The difference between the mean ADC values of benign and malignant lesions was statistically significant $(P$ value $<0.01)$ (Table 4$)$. The highest mean ADC value was among the benign lesions (Figs. 4 and 5), and ameloblastoma had a low ADC values similar to the malignant group.

A threshold ADC value for differentiating malignant from benign lesions derived with receiver operating characteristic analysis (ROC Curve) equals $=1.0 \times 10^{-3} \mathrm{~s} / \mathrm{mm}^{2}$ (Fig. 6). The statistical data obtained were yielding $94 \%$

Table 3 Distribution of the studied cases according to diffusion signal intensity \% from the total at high $b$ value

\begin{tabular}{|c|c|c|c|c|c|}
\hline \multirow{2}{*}{\multicolumn{2}{|c|}{$\begin{array}{l}\text { DWI high } b \text { values } \\
\left(800,1000 \mathrm{~s} / \mathrm{mm}^{2}\right)\end{array}$}} & & \multicolumn{2}{|l|}{ Biopsy } & \multirow[t]{2}{*}{ Total } \\
\hline & & & Benign & Malignant & \\
\hline \multirow{2}{*}{\multicolumn{2}{|c|}{ Low SI }} & $N$ & 28 & 0 & 28 \\
\hline & & $\%$ & $87.5 \%$ & $7.1 \%$ & $50.0 \%$ \\
\hline \multirow{2}{*}{\multicolumn{2}{|c|}{ High SI }} & $N$ & 4 & 28 & 32 \\
\hline & & $\%$ & $12.5 \%$ & $92.9 \%$ & $50.0 \%$ \\
\hline \multirow{2}{*}{\multicolumn{2}{|c|}{ Total }} & $N$ & 32 & 28 & 60 \\
\hline & & $\%$ & $100.0 \%$ & $100.0 \%$ & $100.0 \%$ \\
\hline \multirow[t]{2}{*}{ Chi-square } & $x^{2}$ & \multicolumn{4}{|c|}{17.286} \\
\hline & $P$ value & \multicolumn{4}{|c|}{$0.001^{*}$} \\
\hline
\end{tabular}

SI signal intensity, DWI diffusion-weighted image 

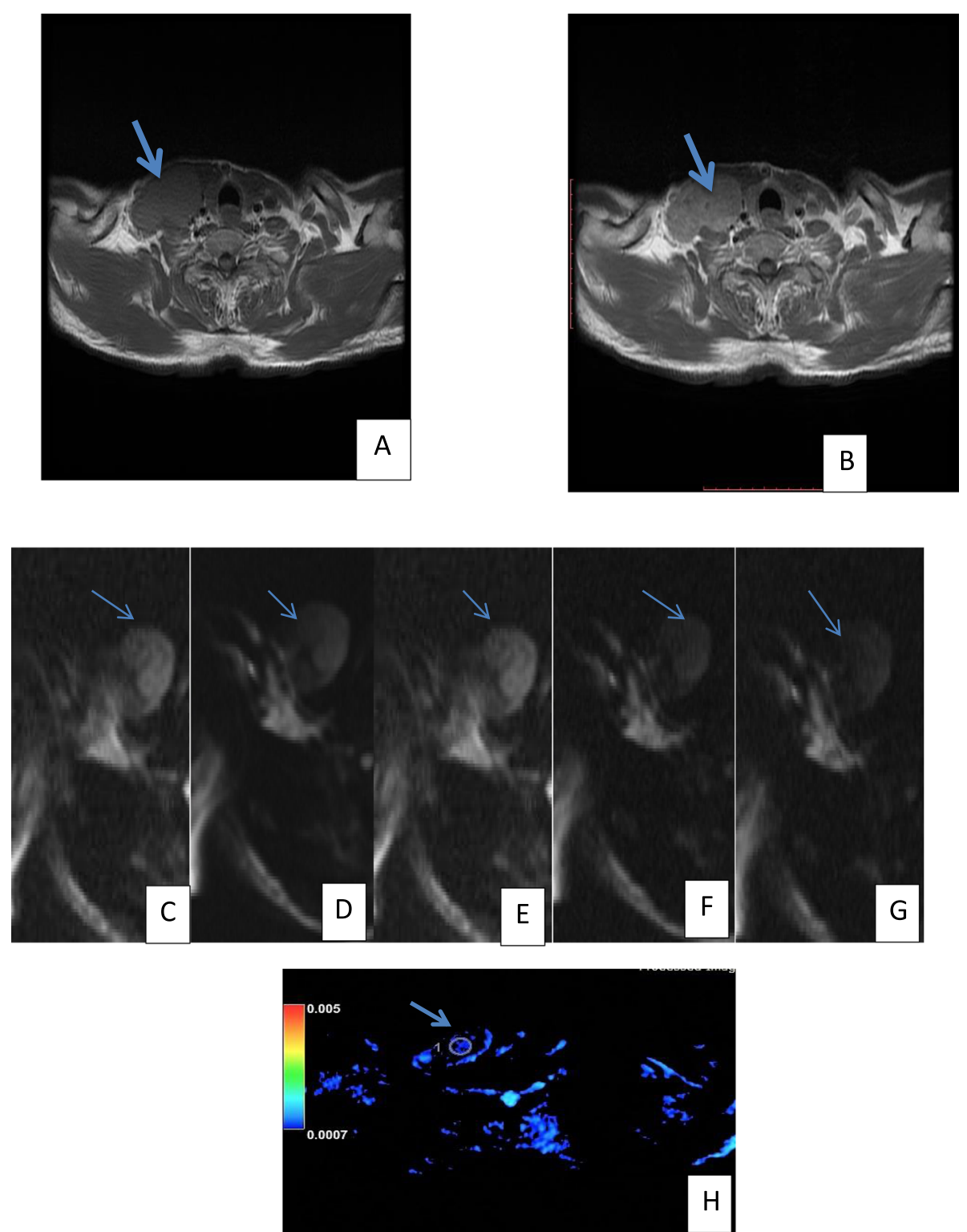

Fig. 1 Sixty-four-year-old male with metastatic anaplastic carcinoma to right supraclavicular lymph node. a Axial T1. b Axial T1 + C. c-g Axial diffusion-weighted imaging with b values: 0, 50, 400, 800, and 1000 respectively. $\mathbf{h}$ ADC map showed a well-defined right supraclavicular neck mass appeared isointense signal in T1 and definite homogenous enhancement after IV contrast; the mass showed central satellite appearance and outer lobulations and elicited high signal in DWI, in both low and high $b$ values (restricted diffusion), ADC value $=0.69 \times 10^{-3} \mathrm{~s} / \mathrm{mm}^{2}(\mathrm{low})$

sensitivity, 93\% specificity, NPV =94\%, and PPV $=93 \%$, accuracy $93.5 \%$ (Table 5).

\section{Discussion}

Accurate in vivo diagnosis and characterization of the solid head and neck masses were very important and affected the plane of management; late diagnoses reflected on morbidity and mortality rate. DWI-MRI was a nonenhanced contrast technique in single breath-hold and showed promising results in improving the diagnostic accuracy $[9,10]$.
Our purpose was to evaluate the value of (DW-MRI) in the characterization of solid head and neck masses with concern to the appropriate $b$ value range; low $\left(0,50,400 \mathrm{~s} / \mathrm{mm}^{2}\right)$ or high (800 and $1000 \mathrm{~s} / \mathrm{mm}^{2}$ ) was more significant with comparing apparent diffusion coefficient (ADC) values.

A $b$ value of $800-1000 \mathrm{~s} / \mathrm{mm}^{2}$ would provide an excellent spatial resolution and an adequate signal/noise ratio for lesion evaluation. The use of $b$ values more than $1000 \mathrm{~s} / \mathrm{mm}^{2}$ would offer better contrast but was more liable to suffer susceptibility artifact. On the other hand, the use of $b$ values lower than $300 \mathrm{~s} / \mathrm{mm}^{2}$ will lead to 

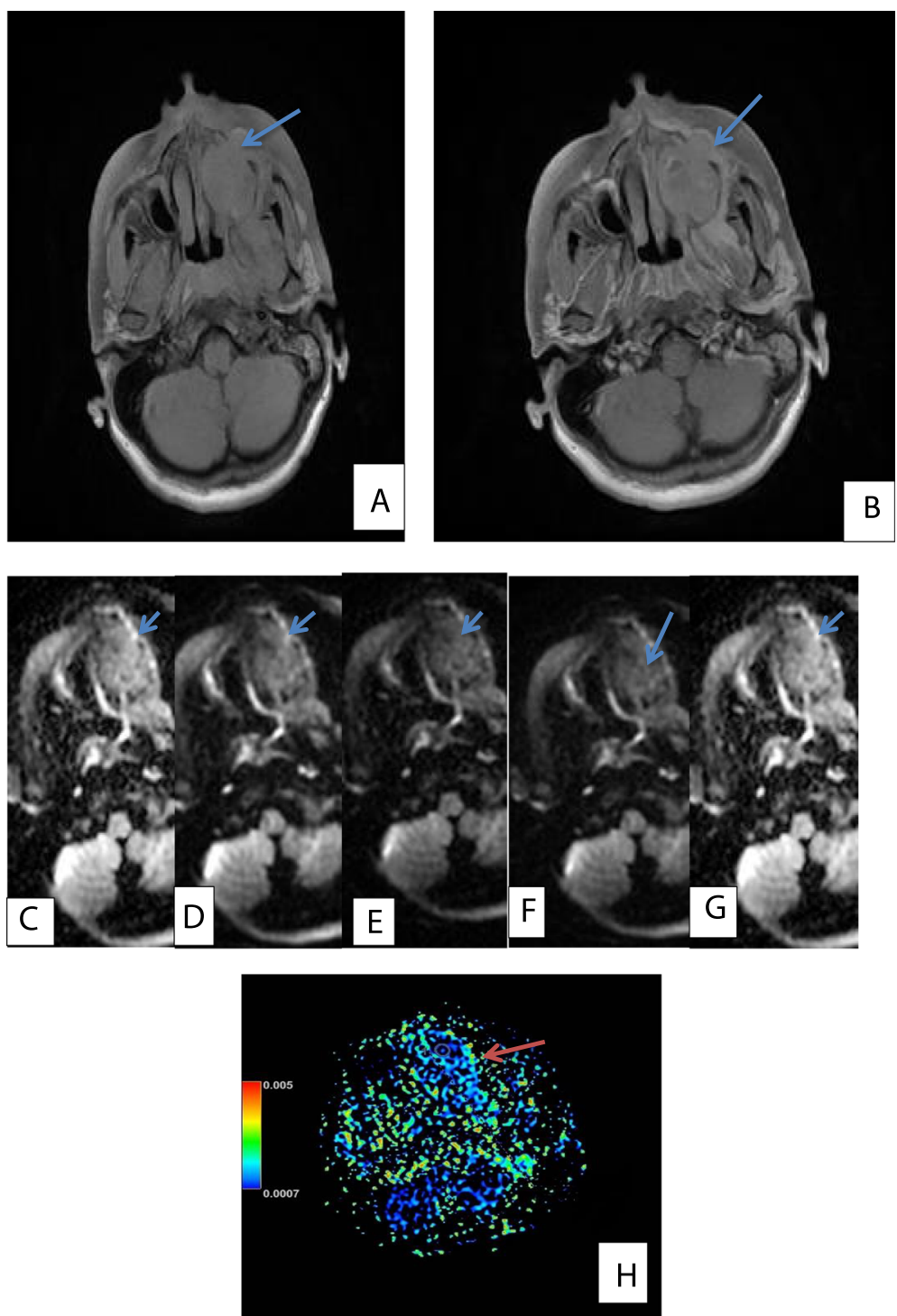

Fig. 2 Thirty- five-year-old female patient with adenoid cystic carcinoma of salivary gland centered upon the left maxillary sinus. a Axial T1. b Axial T1 + C. c-g Axial diffusion-weighted imaging with $b$ values: 50, 400, 800, and 1000 respectively, h) ADC map, it displayed low signal intensity in T1, with homogeneous enhancement after IV contrast, while the cystic parts show no enhancement. The lesion elicited high signal intensity in DWI, in both low and high $b$ values (cystic areas are excluded) with corresponding low signal intensity in ADC map (restricted diffusion), ADC value $=0.77 \times 10^{-3} \mathrm{~s} / \mathrm{mm}^{2}$ (low)

overestimated $\mathrm{ADC}$ values, due to the effect of perfusion of small blood vessels [11]. This was in agreement with our study that had been conducted on 60 patients with solid masses; DWI with the use of high $b$ value 800 and $1000 \mathrm{~s} / \mathrm{mm}^{2}$ was of higher significance $\left(P\right.$ value $\left.0.001^{*}\right)$ in differentiation between benign and malignant lesions than that with low $b$ values 0,50 , and $400 \mathrm{~s} / \mathrm{mm}^{2}$ $(P$ value $0.010 *)$.

In our study, all malignant lesions showed restricted diffusion; this was evidenced by retained high signal on $b$ value $1000 \mathrm{~s} / \mathrm{mm}^{2}$ and hypointensity on ADC maps, in addition to eight benign lesions (ameloblastoma and submandibular adenitis) which showed restricted diffusion while the lesions that lost signal on $b$ value $1000 \mathrm{~s} / \mathrm{mm}^{2}$ and were hyperintense on ADC maps were characterized as having free diffusion was $75 \%$ of benign lesions $(n=24)$. The mean ADC value of malignant lesions was lower than the mean ADC value of benign lesions. The difference between the mean ADC values of benign and malignant lesions was statistically significant $(P$ value $<0.01)$. A threshold ADC value for differentiating malignant from benign lesions equals $=1.0 \times 10^{-3} \mathrm{~s} / \mathrm{mm}^{2}$ with $94 \%$ sensitivity, 93\% specificity, NPV $=94 \%, \mathrm{PPV}=93 \%$, and accuracy $93.5 \%$. That was in line with a study including 33 

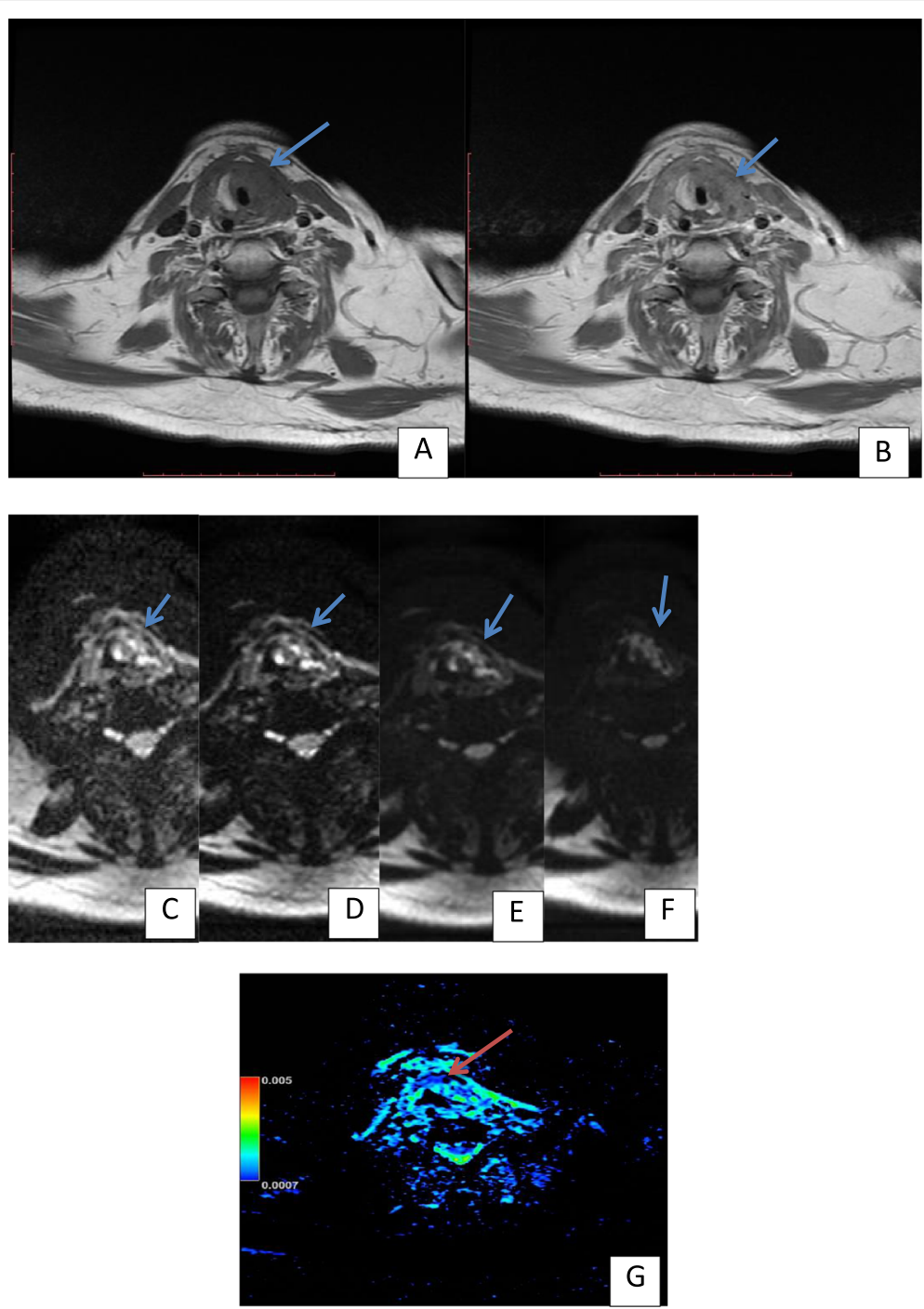

Fig. 3 Sixty-four-year-old male patient with invasive laryngeal squamous cell carcinoma grade 2. a Axial T1. b Axial T1 + C. c-f Axial diffusionweighted imaging with $b$ values: 50, 400, 800, and 1000 respectively. $\mathbf{g}$ ADC map. The mass showed isointense signal in T1 with small areas of necrosis, homogenous enhancement of solid tissue after IV contrast. It elicited high signal in DWI, in both low and high $b$ values with corresponding low signal intensity in ADC map (restricted diffusion), ADC value $=0.607 \times 10^{-3} \mathrm{~s} / \mathrm{mm}^{2}$ (low)

patients (17 benign, 16 malignant lesions) performed on a 3-T MR unit using $b$ values of 0 and $800 \mathrm{~s} / \mathrm{mm}^{2}$ which was able to differentiate benign and malignant lesions using a threshold value of $1.3 \times 10^{-3} \mathrm{~s} / \mathrm{mm}^{2}$ [12]. These results were confirmed also in a study performed on 78 pediatric patients on a 1.5-T MR unit. In these studies, $b$

Table $4 \mathrm{ADC}$ range in benign and malignant lesions in our study

\begin{tabular}{lll}
\hline ADC & Benign & Malignant \\
\hline Range & $0.674-2.590$ & $0.530-1.290$ \\
Mean \pm SD & $2.05 \pm 0.46$ & $0.82 \pm 0.19$ \\
$T$ test & 9.787 & \\
$P$ value & $0.001^{*}$ & \\
\hline
\end{tabular}

values of 0,500 , and $1000 \mathrm{~s} / \mathrm{mm}^{2}$ were applied, and the ADC value for malignant tumors was $0.93 \pm 0.18 \times 10^{-3} \mathrm{~s} /$ $\mathrm{mm}^{2}$, and $1.57 \pm 0.26 \times 10^{-3} \mathrm{~s} / \mathrm{mm}^{2}$ for benign solid masses. Using a threshold ADC value of $1.25 \times 10^{-3} \mathrm{~s} /$ $\mathrm{mm}^{2}$, an accuracy of $92.8 \%$, sensitivity of $94.4 \%$, specificity of $91.2 \%$, and positive predictive value of $91 \%$ and a negative predictive value of $94.2 \%$ were reported [13]. This also was similar to Kanmaz and Karavas [14] that found mean $\mathrm{ADC}$ values of benign and malignant neck masses were $1.57 \times 10^{-3} \mathrm{~s} / \mathrm{mm}^{2}$ and $0.90 \times 10^{-3} \mathrm{~s} / \mathrm{mm}^{2}$, respectively. The difference between the mean ADC value of benign and malignant neck masses was statistically significant $(p<0.01)$.

Eight benign lesions (ameloblastoma and submandibular adenitis) showed restricted diffusion in spite of being 

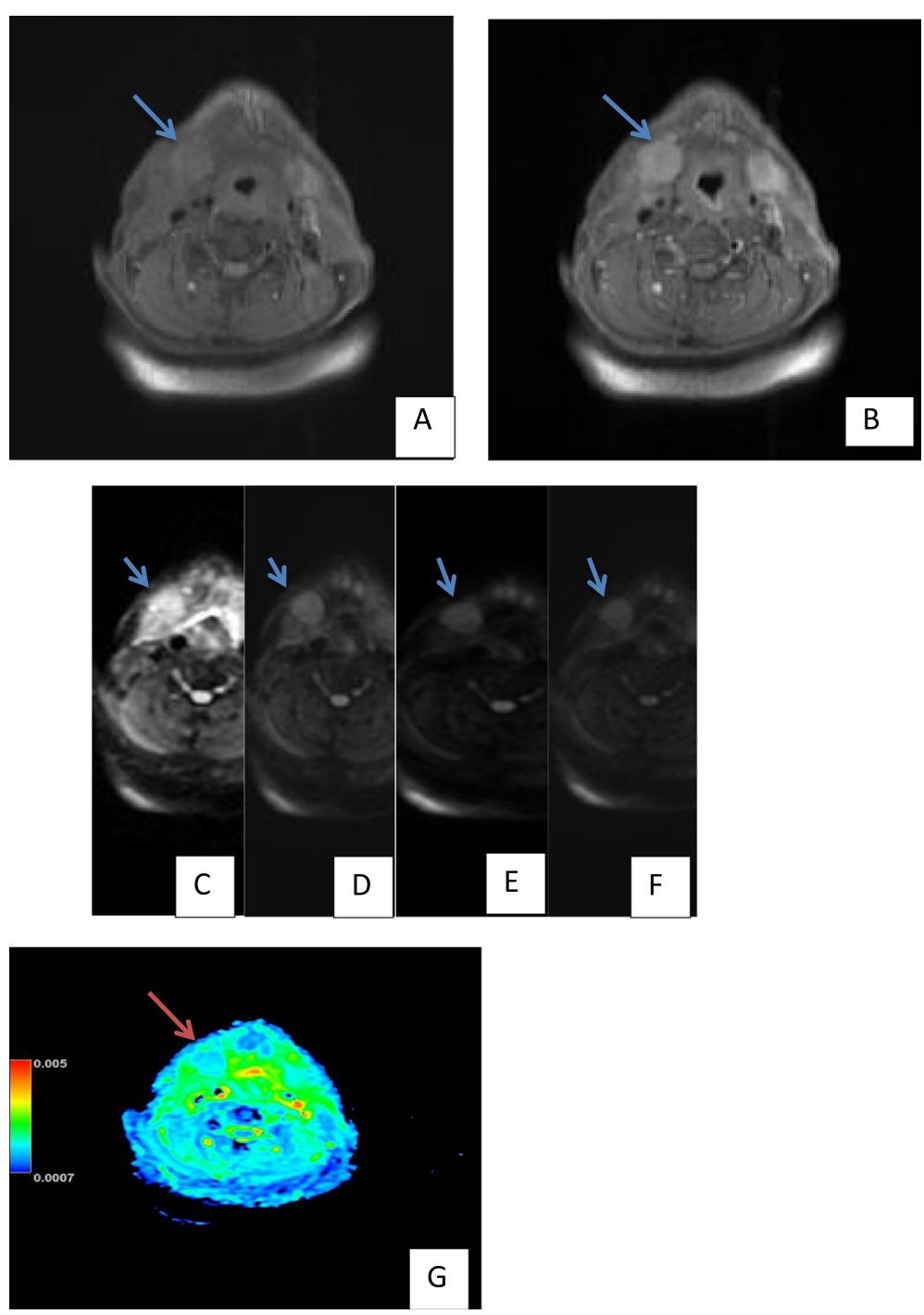

Fig. 4 Thirty-three-year-old female patient with right submandibular lymphadenitis. a Axial T1. b Axial T1 + C. c-f Axial diffusion-weighted imaging with $b$ values: 50, 400, 800, and 1000 respectively. g ADC map axial images showed mild enlarged right submandibular gland with no focal lesion; it displays homogeneous isointense signal intensity in T1, homogenous enhancement after IV contrast. The gland elicits high signal intensity in DWI, in both low and high $b$ values, with corresponding intermediate signal intensity in ADC map (partially restricted diffusion), ADC value $=1.67 \times 10^{-3} \mathrm{~s} / \mathrm{mm}^{2}$ (intermediate)

benign. Ameloblastoma is the most common benign odontogenic tumors, accounting for approximately $11 \%$ of all tumors in the jaw. They usually present as a multilocular lesion with mixed solid and cystic components and marked enhancement of solid components, walls, and septae [15]. ADC value of solid part in ameloblastoma in our study was $0.674 \times 10^{-3} \mathrm{~s} / \mathrm{mm}^{2}$ and shows restricted diffusion which is in agreement with Srinivasan et al. [16], of which in their study, the solid areas of ameloblastoma showed restricted diffusion and low ADC values $\left(1.041 \pm 0.41 \times 10^{-3} \mathrm{~s} / \mathrm{mm}^{2}\right)$, which could be attributed to high tumor cellularity and a greater nucleus to-cytoplasm ratio. Submandibular adenitis in addition to the inflammatory process that caused restriction of diffusion of submandibular gland was one of the normal anatomical structures that gave variable hyper-intensity at high $b$ values and should not be confused with diffusion restriction in tumoral lesions [17].

Characterization and differentiation between neoplastic and reactive lymph nodes were also one of the main purposes of performing DW-MRI in neck cancer studies [18]. Metastatic adenopathies could be detected in imaging studies early before clinical examination even in inaccessible locations such as retropharyngeal or paratracheal lymph chains [19]. SCC (squamous cell carcinoma) is the most common type of cancer in the head and neck, and it usually spread through the lymphatic system to cervical nodes [20]. 

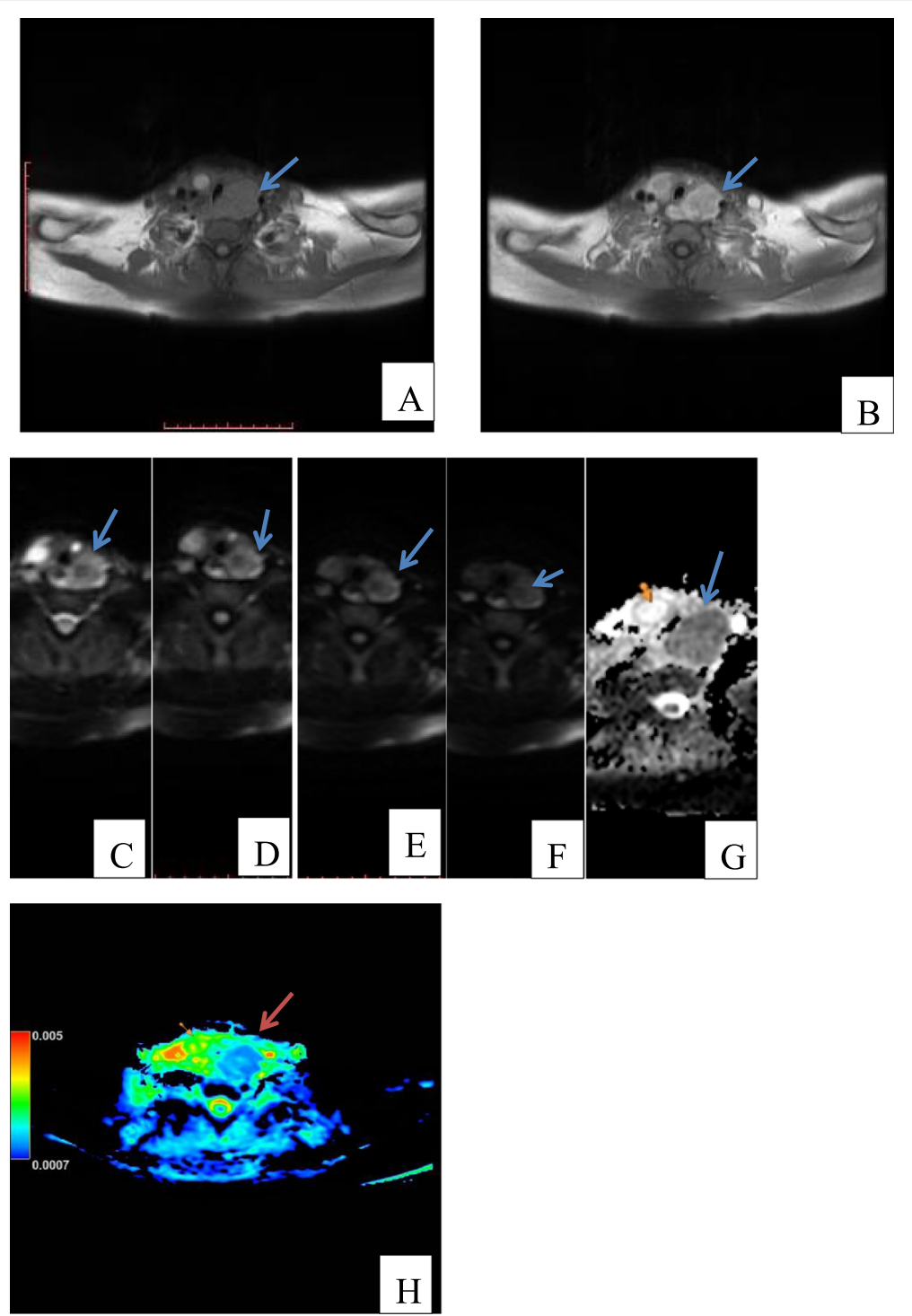

Fig. 5 Twenty-two-year-old female patient with nodular goiter. a Axial T1. b Axial T1 with contrast. $\mathbf{d}$-f Axial diffusion-weighted imaging with $b$ values: 50, 400, 800, and 1000 respectively. g ADC map (gray). h ADC map (colored) showed multiple thyroid nodules detected in both thyroid lobes, the largest at right thyroid. The nodules showed high signal intensity in $\mathrm{T} 1$ and peripheral ring enhancement after IV contrast. It elicited high signal in DWI, in low $b$ values, with rapid signal decayed in high $b$ values, showing the same signal intensity of normal thyroid tissue at $b$ value 1000, with corresponding high signal intensity at ADC map (free diffusion), ADC value $=2.21 \times 10^{-3} \mathrm{~s} / \mathrm{mm}^{2}$ (high)

Our study had revealed that mean ADC values in metastatic node $(n=10)$ \{range $(0.530-0.815) \times 10^{-3} \mathrm{~s} / \mathrm{mm}^{2}$ \} mean $0.691 \times 10^{-3} \mathrm{~s} / \mathrm{mm}^{2}$ were significantly lower than that of benign nodes $(n=14)\left\{\right.$ range $(1.86-2.45) \times 10^{-3} \mathrm{~s} / \mathrm{mm}^{2}$ \} mean $2.11 \times 10^{-3} \mathrm{~s} / \mathrm{mm}^{2}$. Li et al. [21] had shown that the mean ADC between metastatic and non-metastatic retropharyngeal nodes were statistically significant differences by DWI $(P<0.001)$. Holzapfel et al. [22] had also demonstrated that mean ADC values $\left(\times 10^{-3} \mathrm{~s} / \mathrm{mm}^{2}\right)$ of benign cervical lymph nodes $(1.24 \pm 0.16)$ were significantly higher than that of metastatic lymph nodes $(0.78 \pm 0.09)$.

Another important diagnostic issue in daily clinical routine MRI examination was an evaluation of incidental thyroid nodules. Lower ADC values were reported in malignant lesions [23]. Erdem et al. in their published study consisting of 52 benign and 9 malignant nodules found that the mean ADC values of malignant thyroid nodules $\left(0.69 \pm 0.31 \times 10^{-3} \mathrm{~s} / \mathrm{mm}^{2}\right)$ were significantly lower than those of benign nodules $\left(2.74 \pm 0.60 \times 10^{-3} \mathrm{~s}\right.$ / $\mathrm{mm}^{2}$ ) [24], and Seyedmehdi [25] used a 1.5-T scanner with SS EPI acquisition and $b$ values of 0,250 , and 500 $\mathrm{s} / \mathrm{mm}^{2}$ and showed that mean ADC value of malignant solitary thyroid nodules $\left(0.73 \pm 0.19 \times 10^{-3} \mathrm{~s} / \mathrm{mm}^{2}\right)$ was significantly lower than benign nodules $(1.8 \pm 0.27 \times$ $10^{-3} \mathrm{~s} / \mathrm{mm}^{2}$ ). This result is similar to our study; two cases of thyroid cancer giving ADC value $0.924 \times 10^{-3} \mathrm{~s} /$ 


\section{ROC Curve}

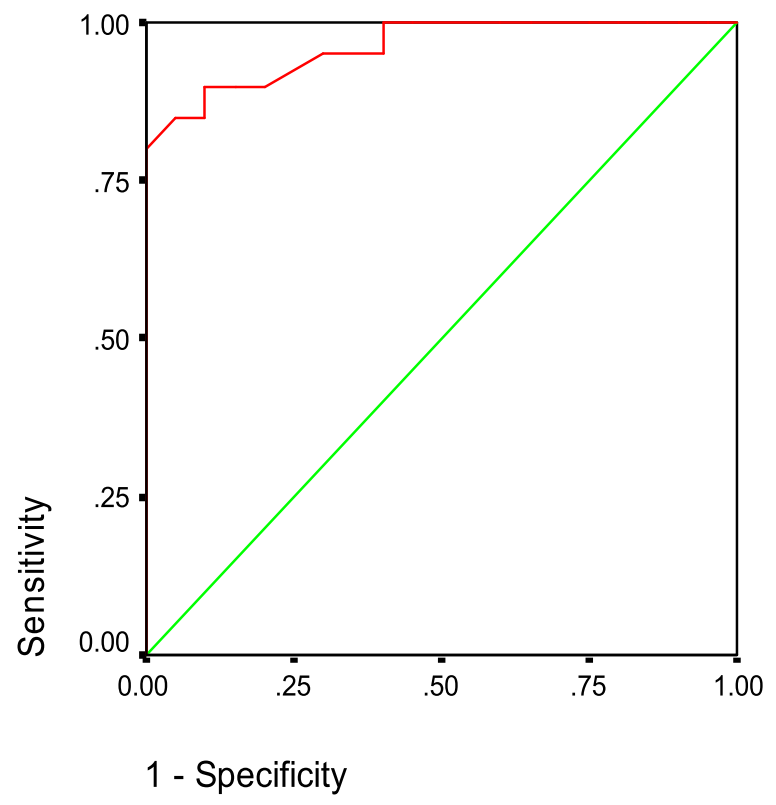

Diagonal segments are produced by ties.

Fig. 6 Receiver operating characteristic (ROC) curve of the ADC values for differentiation between benign and malignant solid neck masses. The area under the curve (AUC) was 0.946

$\mathrm{mm}^{2}$ were significantly lower than those of benign nodules $(n=8$ with ADC value ranging between 2.16 and 2.26 $\left(\times 10^{-3} \mathrm{~s} / \mathrm{mm}^{2}\right)$. Contrary to the previously mentioned study, Schueller-Weidekamm et al.'s study on 35 cold thyroid nodules were investigated by DWI with a $b$ factor of $800 \mathrm{~s} / \mathrm{mm}^{2}$; they found median ADC values for carcinoma, adenoma, and Hashimoto thyroiditis as $2.73 \times$ $10^{-3} \mathrm{~s} / \mathrm{mm}^{2}, 1.93 \times 10^{-3} \mathrm{~s} / \mathrm{mm}^{2}$, and $3.46 \times 10^{-3} \mathrm{~s} / \mathrm{mm}^{2}$, respectively [26]. They concluded the high $\mathrm{ADC}$ value in thyroid cancer, as a result of macrofollicular production of thyroglobulin, diffusion capacity can be unrestricted. Additionally, the presence of microcalcifications affects $M R$ signal intensity [27].

Squamous cell carcinoma (SCC) is the most common malignant pathology in the head and neck region, commonly involving regional lymph nodes [28]. This was evident in our study where $57.14 \%(n=16)$ of malignant cases $(n=28)$ were SCC; the ADC value of lesions was low ranging between $(0.530$ and 1.29$) \times 10^{-3} \mathrm{~s} / \mathrm{mm}^{2}$.

We conclude that DW-MRI with high $b$ values had higher significance than low $b$ values as low $b$ value

Table 5 A threshold ADC value for differentiating malignant from benign lesions and the statistical data obtained

\begin{tabular}{cccccccc}
\hline & Cutoff & AUC & Sensitivity & Specificity & PPV & NPV & Accuracy \\
\hline ADC & 1.0 & 0.946 & 94 & 93 & 93 & 94 & 93.5 \\
\hline
\end{tabular}

DW-MRI became less qualitative and more quantitative, so it must be based on complex ADC calculations.

Limitations of our study include unavoidable image distortion to some degree in DWI due to magnetic susceptibility artifact yet did not hinder adequate ADC calculation and a relatively small sample of cases that may decrease the accuracy of statistical analysis.

\section{Conclusion}

Technical point should be put into consideration in DWI-MRI and ADC mapping in head and neck region to use high $b$ values as it had higher significance as a non-invasive tool in differentiating between benign and malignant solid head and neck masses with highly significant difference between ADC values of benign and malignant masses. Qualitative (DW-MRI) and quantitative (ADC) assessment were helpful in resolving many diagnostic problems in imaging head and neck masses when accompanying routine conventional MRI.

\section{Abbreviations}

DWI: Diffusion-weighted imaging; MRI: Magnetic resonant imaging:

ADC: Apparent diffusion coefficient; SI: Signal intensity; SNR: Signal to noise ratio

\section{Acknowledgements}

The authors acknowledge all the participants for their cooperation and patience.

\section{Authors' contributions}

RA correlated the study concept and design, had a major role in the analysis, collected the data in all stages of manuscript, and performed the data

analysis; $\mathrm{HH}$ supervised the study with significant contribution to design the methodology, manuscript revision, and preparation. Both authors read and approved the final manuscript.

\section{Funding}

No funding. Not applicable for this section.

\section{Availability of data and materials}

The authors confirm that all data supporting the finding of the study are available within the article, and the raw data supporting the findings were generated and available at the corresponding author on request.

\section{Ethics approval and consent to participate}

Informed written consent was taken from the patients and healthy volunteers; the study was approved by ethical committee of Tanta University Hospital, Faculty of Medicine. Number 4416-2019.

\section{Consent for publication}

All participants included in the research gave written consent to publish the data included in the study. Authors accepted to publish the paper.

\section{Competing interests}

The authors declare that they have no competing interests.

Received: 11 July 2019 Accepted: 23 September 2019

Published online: 26 November 2019

\section{References}

1. Grégorie V, Lefebvre JL, Licitra F et al (2010) Squamous cell carcinoma of the head and neck: clinical practice guidelines for diagnosis, treatment and follow-up. Ann Oncol 21:184-186 
2. Franca C, Levin-Plotnik D, Sehgal VC et al (2000) Use of three-dimensional spiral computed tomography imaging for staging and surgical planning of head and neck cancer. J Digit Imaging 13:24-32

3. Panebianco V, Barchetti F, Sciarra A et al (2013) Prostate cancer recurrence after radical prostatectomy: the role of 3-T diffusion imaging in multiparametric magnetic resonance imaging. Eur Radiol 6(23):1745-1752

4. Attariwala R, Picker W, Whole body MRI (2013) Improved lesion detection and characterization with diffusion weighted techniques. J Magn Reson Imaging 38(2):253-268

5. Tang Y, Zhou Y, Wei D et al (2014) Standard b-value versus low b-value diffusion-weighted MRI in renal cell carcinoma: a systematic review and meta-analysis. BMC Cancer 14:843-851

6. Bhatt N, Gupta N, Soni N, Hooda K et al (2017) Role of diffusion-weighted imaging in head and neck lesions: pictorial review. Neuroradiol J 30(4):356369

7. Hermans R, de Keyzer F, Vandecaveye $V$ et al (2012) Imaging techniques. In: Head and neck cancer imaging, vol 3. Springer, Berlin/Heidelberg, pp 33-54

8. El Shahat HM, Fahmy HS, Gouhar GK (2013) Characterization of head and neck lesions with diffusion-weighted MR imaging and the apparent diffusion coefficient values. Egypt J Radiol Nucl Med 44:791-798

9. Taha MS, Hassan O, Amir M et al (2014) MRI in diagnosing thyroid cartilage invasion in laryngeal carcinoma. Eur Arch Otorhinolaryngol 271:2511-2516

10. Thoeny HC, De Keyzer F, Claus FG et al (2015) Gustatory stimulation changes the apparent diffusion coefficient of salivary glands: initial experience. Radiology 235(34):629

11. Verhappen MH, Pouwels PJ, Ljumanovic R et al (2012) Diffusion-weighted MR imaging in head and neck cancer: comparison between half-fourier acquired single-shot turbo spin-echo and EPI techniques. Am J Neuroradiol 33:1239-1246

12. Srinivasan A, Dvorak R, Perni K et al (2008) Differentiation of benign and malignant pathology in the head and neck using $3 \mathrm{~T}$ apparent diffusion coefficient values: early experience. AJNR Am J Neuroradiol 29(1):40-44

13. Abdel Razek AA, Gaballa G, Elhawarey G et al (2009) Characterization of pediatric head and neck masses with diffusion-weighted MR imaging. Eur Radiol 19:201-208

14. Kanmaz L, Karavas E (2018) The role of diffusion-weighted magnetic resonance imaging in the differentiation of head and neck masses. J Clin Med 7(6):130

15. Kaneda T, Minami M, Kurabayashi T (2003) Benign odontogenic tumours of the mandible and maxilla. Neuroimaging Clin N Am 13:495-507

16. Srinivasan K, Bhalla AS, Sharma R et al (2012) Diffusion-weighted imaging in the evaluation of odontogenic cysts and tumors. Brit J Radiol 85:864-870

17. Roth Y, Tichler T, Kostenich $G$ et al (2004) High-b-value diffusion-weighted MR-imaging for pre-treatment prediction and early monitoring of tumor response to therapy in mice. Radiology. 232:685-692

18. Sumi M, Nakamura T (2013) Assessment of perfusion-related parameters and diffusion coefficients based on the intravoxel incoherent motion model. Am J Neuroradiol 34(2):410-416

19. Maeda M, Maier SE (2008) Usefulness of diffusion-weighted imaging and the apparent diffusion coefficient in the assessment of head and neck tumors. J Neuroradiol 35:71-78

20. Maeda M, Kato H, Sakuma H et al (2005) Usefulness of the apparent diffusion coefficient in line scan diffusion-weighted imaging for distinguishing between squamous cell carcinomas and malignant lymphomas of the head and neck. AJNR Am J Neuroradiol 26(5):1186-1192

21. Li H, Liu XW, Geng ZJ et al (2015) Diffusion-weighted imaging to differentiate metastatic from non-metastatic retropharyngeal lymph nodes in nasopharyngeal carcinoma. Dentomaxillofac Radiol 44:1-19

22. Holzapfel K, Duetsch S, Fauser C et al (2009) Value of diffusion-weighted MR imaging in the differentiation between benign and malignant cervical lymph nodes. Eur J Radiol 72:381-387

23. Harriet C, Thoeny MD (2010) Diffusion-weighted MRI in head and neck radiology: applications in oncology. Cancer Imaging 10:209-214

24. Erdem G, Erdem T, Muammer $\mathrm{H}$ et al (2010) Diffusion-weighted images differentiate benign from malignant thyroid nodules. J Mag Reson Imaging 31(1):94-100

25. Seyedmehdi P (2018) Quantitative diffusion magnetic resonance imaging in head and neck tumors. Quant Imaging Med Surg 8:10

26. Schueller-Weidekamm C, Schueller G, Kaserer K et al (2010) Diagnostic value of sonography, ultrasound-guided fine-needle aspiration cytology, and diffusion-weighted MRI in the characterization of cold thyroid nodules. Eur J Radiol 73(3):538-534

27. Bozgeyik Z, Sonay C, Ferda Dagli A et al (2009) Diffusion-weighted MR imaging of thyroid nodules. Neuroradiology 51:193-198

28. Togan T, Hossam M, Mohamed S et al (2015) Role of diffusion weighted MRI in the initial diagnosis and follow-up of pharyngeal squamous cell carcinoma. Egypt J Radiol Nucl Med 46:919-927

\section{Publisher's Note}

Springer Nature remains neutral with regard to jurisdictional claims in published maps and institutional affiliations.

\section{Submit your manuscript to a SpringerOpen ${ }^{\circ}$ journal and benefit from:}

- Convenient online submission

- Rigorous peer review

- Open access: articles freely available online

- High visibility within the field

- Retaining the copyright to your article

Submit your next manuscript at $>$ springeropen.com 